\title{
Retrospective Evaluation of the Last 10 Years Development of Particle (Proton, Carbon) Radiotherapy Centers
}

\section{Parçacık (Proton, Karbon) Radyoterapi Merkezlerinin Son 10 yıllık Gelişiminin Retrospektif Değerlendirmesi}

\author{
Fatih Göksel
}

S.B.Ü. Dr. A. Yurtaslan Ankara Onkoloji E.A.H. Radyasyon Onkolojisi Kliniği, Ankara

Dergiye Ulaşma Tarihi: 09.03.2020 Dergiye Kabul Tarihi: 20.03.2020 Doi: 10.5505/aot.2020.57704

\section{ÖZET}

GİRIŞ ve AMAÇ: Parçacık tedavisinin dünyada yaygınlığı, gelişimi, kapasitesi ve gelecekteki durumu ile tedavi edilen hasta ve parçacık tedavi merkez sayılarının son 10 yıllık dönemde değişiminin değerlendirilmesi amaçlanmıştır. Ayrıca çalışmamızda kanser tedavisinde en son teknoloji ve güncel yöntemler uygulanan ülkemizde şu anda bulunmayan parçacık radyoterapi sistemlerin kurulumu, planlanması ve ihtiyacın belirlenmesine katkı sağlanması da amaçlanmıştır.

YÖNTEM ve GEREÇLER: Çalışmada, dünya genelinde parçacık radyoterapi sistemlerini kullanan merkezlerin; kurulum tarihleri, tedavi oda sayıları, kurulum süreci, planlama aşaması ve tedavi edilen hasta sayılarına yönelik bilgilerine ulaşıldı. Bu merkezlerin 2010 - 2020 yılları arasındaki verileri merkez, tedavi oda sayısı ve tedavi edilen hasta sayıları ve yıl bazlı oranları retrospektif olarak değerlendirilmiştir.

BULGULAR: Dünyada parçacık tedavi sistemine sahip 2010 yılında 9 ülke varken 2020 yılında bu rakam 19 ülkeye çıkmıştır. İnşaatı devam eden parçacık radyoterapi merkezleri ile birlikte 25 ülkeye, karbon radyoterapi sisteminde 8 ülkeye çıkacağı görülmektedir.

Tedavi merkez sayıları yönünden baktığımızda 2010 yılında toplamda 31 merkez olup bunun; 26 tanesi proton, 3 tanesi karbon ve 2 tanesi proton+karbon iken 2020 y1lında bu rakamlar toplamda 96 merkeze çıkmış olup bunun da 83 tanesi proton, 7 tanesi karbon ve 6 tanesi proton+ karbon tedavi merkezidir. Planlama aşamasındaki merkezleri de dikkate aldığımızda toplamda 161 merkeze çıkacaktır.

Parçacık radyoterapisi ile tedavi olan hasta sayıları 2010 yılında 76.266 iken 2018 yılında bu rakam 221.528'lere ulaşmıştır. Tedavi odası başı yıllık tedavi edilen yeni hasta sayıları protonda 86-197 yeni hasta/yıl aralığında olup karbon tedavisinde 28-211 yeni hasta/yıl aralığındadır.

TARTIŞMA ve SONUÇ: Özellikle sağlık sektöründeki gelişmeler sayesinde ülkemiz bölgemizin referans hastaneleri ve merkezleri konumuna gelmiştir. Dünyadaki durum ve ülkemizin içinde bulunduğu durum düşünüldüğünde bu özelliğimizinin devam edebilmesi için ülkemizin proton tedavisi yanı sıra karbon tedavisine de geçmesi gerektiği görülmektedir

Anahtar Kelimeler: Parçacık Tedavisi, Parçacık Radyoterapisi, Karbon, Proton

\section{ABSTRACT}

INTRODUCTION: The aim of this study is to evaluate the extent, development, capacity and future status of the particle treatment in the world and the change in the number of patients and particle treatment centers treated in the last 10 years. In addition, in our study, it is aimed to contribute to the establishment, planning and determination of the need for particle radiotherapy systems that are not currently available in our country where the latest technology and current methods in cancer treatment are applied.

METHODS: In the study, the centers using particle radiotherapy systems worldwide; information on the dates of installation, number of treatment rooms, installation process, planning stage and number of patients treated were reached. The data of these centers between 2010 and 2020 were evaluated retrospectively based on the center, number of treatment rooms and number of patients treated, rates.

RESULTS: While there were 9 countries in the world with a particle treatment system in 2010, this figure increased to 19 countries in 2020. When particle radiotherapy centers are included, the number of centers will increase to 25 countries, while carbon radiotherapy systems will increase to 8 countries. When we look at the 
number of treatment centers in 2010, there are 31 centers in total; 26 of them are protons, 3 of them are carbon and 2 of them are proton+ carbon. In 2020, these numbers have increased to 96 centers, of which 83 are proton, 7 are carbon and 6 are proton+ carbon treatment centers. When we consider the centers in the planning stage, it will increase to 161 centers in total. While the number of patients treated with particle radiotherapy was 76,266 in 2010, this figure reached 221,528 in 2018. The number of new patients treated annually per treatment room is in the range of 86-197 new patients/years in Proton and in the range of 28-211 new patients/years in carbon therapy.

DISCUSSION AND CONCLUSION: Thanks to the developments in the health sector, our country has become the reference hospitals and centers of our region. Considering the situation in the world and the situation our country is in, it is seen that in order for this feature to continue, our country should switch to carbon therapy in addition to proton therapy.

Keywords: Particle Therapy, Particle Radiotherapy, Carbon, Proton

\section{GİRIŞ ve AMAÇ}

Kanser, maddi ve manevi yönden uzun süreli mücadele gerektiren tüm toplumlarda ciddi bir sağlık sorunudur. Dünya çapında 2018'de 18.1 milyon insana kanser tanis1 kondu ve 9.6 milyon hasta kanserden öldü. Öngörülen küresel yük 2040'a kadar yaklaşık 29-37 milyon yeni kanser vakası ile iki katına çıkacak ve bu artışın üçte ikisinden fazlasının kaynakları az ya da orta gelir düzeyine sahip ülkelerde olması beklenmektedir. 2018'de 30 ila 69 yaş arasındaki 15 milyon ölümden ("erken ölüm") 4,5 milyonu kansere bağl1 gelişmiştir. Yaşam beklentisi ve epidemiyolojik ve demografik geçişler nedeniyle önümüzdeki yıllarda yeni vaka ve ölümlerin sayısı artmaya devam edeceği öngörülmektedir. Dünya Sağlık Örgütü, kanserden ölümlerin önlenmesinde uygun planlama ve uygulama ile düşük gelirli ülkelerde bile etkili ve uygun fiyatl kanser yönetim sistemlerini kademeli olarak kurulmasını önermektedir. Parçacık tedavisine dayanan ileri kanser tedavisi teknikleri, bu çabada önemli bir rol oynaması beklenen tedavi araçları arasındadır.(1,2)

Kanserde tedavi seçeneği olarak parçacık (proton, karbon) radyoterapisindeki teknolojik gelişmeler oldukça heyecan verici olmakla birlikte yeni bir tedavi yaklaşımı değildir. Tıp alanında tedavide kullanma fikri ilk olarak 1946'da fizikçi Robert R. Wilson tarafindan önerilmiştir. 1930 yılında keşfedilmiş olan yüklü parçacıklar ile hastaları tedavi etmeye yönelik ilk girişimler 1950'lerde nükleer fizik araştırma tesislerinde başlanmıştır. Başlangıçta, klinik uygulamalar vücudun birkaç kısmı ile sinırlıydı. Çünkü hızlandırıcılar yeterince güçlü değildi. 1970'lerin sonlarında, yüksek hızlı bilgisayarlar, hızlandırıcı ve tedavi uygulama teknolojisindeki teknolojik gelişme, Adress for correspondence: T.C.Sağlık Bakanlığıdr. Abdurrahman Yurtaslanankara Onkoloji Eğitim Ve Araştırma Hastanesi, Radyasyon Onkolojisi, Mehmet Akif Ersoy Mah. Vatan Cad. No: 91 Yenimahalle /Ankara Posta Kodu: 06200

e-mail: fatihgoksel@gmail.com

Available at www.actaoncologicaturcica.com

Copyright $\mathbb{C}$ Ankara Onkoloji Hastanesi görüntüleme ve planlama sistemlerindeki ilerlemeler parçacık (proton, karbon) radyoterapisini kanser tedavisinde tıbbi uygulamalar için daha uygun hale getirmiştir. Hastane tabanlı parçacık radyoterapisi ilk olarak 30 y1l önce Loma Linda Üniversitesi Tıp Merkezi'nde başlamıştır. Lineer akseleratörlerin (LINAC doğrusal hızlandırıcı) ürettiği $X$-ışını (foton) ve elektron tedavilerinden proton ve karbonun fark1 doku içinde soğurulma özelliklerinden kaynaklanmaktadır. Teknik olarak doku içinde belli bir derinlikte patlama şeklinde enerjisinin tamamını bıraktığı için bu seviyenin arkasında pratik olarak hiç doz bırakmadığından dokuda hasarda yapmaz. Bunun gibi özelliklerinden yararlanılarak kritik organları ileri derecede koruyarak, tümöre öldürücü dozlar vermeye imkan sağlamaktadır. $(3,4,5)$

Protonun başlica fiziksel özelliği; "Bragg peak" sayesinde fotona göre bariz üstündür. Erişilmesi istenilen derinliğe gelinceye kadar fotona göre enerjisinin daha az bir kısminı normal dokularda birakırken istenilen derinlikte yani tümörlü dokuda kalan enerjisinin tamamını boşaltır ve sıfırlanır. $\mathrm{Bu}$ derinlikten sonra enerjisini tümör içine bıraktığ1 için gereksiz çıkış dozu yoktur, normal dokularda ışınlanma olmaz, dolayısı ile sağlıklı dokulara verilecek olan hasar minimum seviyelerde kalmaktadır. Foton ise vücuda girişinden itibaren enerjisini boşaltarak ilerler, istenilen derinlikte ekstra bir enerji aktarımı olmaz ve tümörden sonra doz bırakmaya devam ederek vücuttan çıkar. Bundan dolayı parçacık tedavisinin fotona göre integral dozu 3 kat daha azdir. Protonun Relative Biyolojik Etkisi fotonlardan \%10-15 kadar daha etkindir. Relative Biyolojik Etki fotonda 1, protonda 1,1 ve karbonda ise derinliğe bağlı olarak 1,2 ile 3,2 arasında değişmektedir. Bu özellikleri ile tam bir ideal 
1şın olmasa da fotona göre daha tercih edilecek bir ışın türüdür. Foton ile yapılan bazı tedavilerde kritik organların sinırlı dozlarından dolayı tümöre istenilen doz verilememektedir. Parçacık ile tedavide ise tümöre daha yüksek dozlar verilebilmektedir. $(3,4,5,6,7,8,9)$

Proton ile en çok tedavi edilen kanserlerin başında uveal melanom gelmektdir. Diğer tedavideki kullanım alanları; pediatrik kanserler, kraniyel yerleşimli tümörler (kondroblastom, kordoma), baş boyun kanserleri, beyin ve spinal kord, pelvis, paraaortik tümörler (seminom) omurga tümörleri, lenfomalar, prostat kanseri, sindirim sistemi kanserleri, meme kanseri, göz, ikinci seri 1şınlamalar v.b. dir. Özellikle lenfoma gibi kesin iyileşme olasılığ hastalarda, radyoterapiye bağlı ikincil kanser olma olasılığ1 \%30'a kadar çıkmaktadır. Genç yaşta görülen bu tür kanserlerin tedavisinde proton öncelikle tercih edilmesi önerilebilir. Protonun, fotona göre normal dokuya bıraktığ 1 radyasyon dozunun daha düşük olması, sadece ikincil kanser riskini azaltmamakta, radyoterapiye bağlı akut ve kronik yan etkileri de azaltmaktadır. $(3,5,6,10,11,12)$

Proton tedavisinin kullanım alanında radyoterapi yapılan kanser türlerinin büyük çoğunluğu girmekle beraber öncelikle pediatrik tümörler yer almaktadır. Çocuklarda, yapılan radyoterapi sonucu oluşabilecek ikincil kanserleri en aza indirmek için tüm vücudun aldığ 1 integral dozu minimumda tutmak temel prensip olup bunu en iyi şekilde proton tedavisi sağlamaktadır. Proton tedavisinin pediatrik tümörlerdeki en önemli başarısı, çocuklarda uzun süreli radyoterapiye bağlı oluşabilecek kalıcı zararlı etkilerde önemli bir düşüşe yol açma olanağı ve ikincil tümör gelişiminde azalma dahil sunarak, tedaviye bağlı morbiditeyi iyileştirmesidir. Böylece çocuklarda radyasyonun uzun dönemdeki olası yan etkileri ve radyasyona bağlı morbiditeyi azalacağından, pediatrik tümörlerin tedavilerinde parçacık radyoterapisinin rolü giderek artmaktadır. Tedavi başarı oranındaki bu önemli artış çok ümit vericidir ve gelecekte, çocukluk çağı tümörlerinde foton tedavilerinin yerini proton tedavilerine birakması sonucunu doğurabilir. $(5,11,12,13)$

Parçacık radyoterapisinin avantajları $(5,6,7,8,11,13,14)$ :
- Fotonlardan biyolojik olarak daha etkilidir ve bu nedenle tedaviye cevap şansını artırabilir. Ek olarak, geleneksel radyoterapiye cevap vermeyen dirençli tümörleri etkili bir şekilde tedavi edilebilir.

- Vücudun derinliklerinde bulunan tümörlere rahatlıkla ulaşabilir. Yüklü parçacıklar (iyonlar) 1şık hızının dörtte birinden fazlasına hızlandırılır ve tümör dokusuna hedeflenir. Hız ve enerjiye bağlı olarak, yüklü parçacıklar doku içinde 30 santimetreye kadar ulaşabilir. Bununla birlikte, fotonlar, daha derin bir tümöre giderken enerjilerinin büyük bir kısmını çevre dokulara bırakmaktadır ve dokunun $3 \mathrm{~cm}$ derinliğine kadar daha etkilidirler.

- Yıkıcı etkiler özellikle ağır iyonlarda güçlüdür. $\mathrm{Bu}$ etki kordomalar ve kondrosarkomlar gibi bazı kanserlerde etkili bir tedavi etme şansı verir.

- İyonlar, tümöre daha kesin bir şekilde ulaşarak, yıkıcı enerjisini daha doğru bir şekilde serbest bırakır - bunu çevreleyen sağlıklı doku korunur ve daha az yan etki gelişir. Bu durum özellikle kafa taban1, optik sinir veya bağırsak gibi hayati dokulara yakın tümörler için önemlidir.

- Proton tedavisi özellikle çocuklarda tercih edilir, çünkü geleneksel tedavilere göre daha fazla çevredeki sağlıklı doku korur ve daha az geç yan etki beklenir. Böylece çocuklarda büyüme-gelişme plakları daha fazla korunur ve ikincil kanser gelişimini azaltır.

Dünyada proton ve karbon harici diğer parçacıklarda tedavi amaçlı kullanılmıştır. Ancak en uygun olduğu düşünülen proton ve karbon üzerinde yoğunlaşılmıştır. Çalışmamızda Türkiye için tamamen yeni olan ve dünyada sınırlı sayıda merkezde çalışmakta olan bu teknolojinin dünyada yaygınlığı, gelişimi, kapasitesi ve gelecekteki durumu ile hasta tedavi sayılarının son 10 yıllık dönemde değişiminin değerlendirilmesi amaçlanmıştır. Çalışmamızda ayrıca kanser tedavisinde en son teknoloji ve güncel yöntemler uygulanan ülkemizde şu anda bulunmayan parçacık radyoterapi sistemlerin kurulumu, planlanmas1 ve ihtiyacın belirlenmesine katkı sağlanması da amaçlanmıştır.

\section{MATERYAL VE METOD}

Çalışmada, dünya genelinde parçacık (proton, karbon) radyoterapisi sistemlerini kullanan merkezler ile iletişim, yayınlanan 
literatürlerin takibi, kongreler sırasında ilgili merkezlerle veri paylaşımı ve elektronik veri tabanlarının taranması gibi yöntemlerden faydalanarak merkezlerin; kurulum tarihleri, tedavi oda sayıları, tedavi teknolojisi, kurulum süreci, planlama aşaması ve tedavi edilen hasta sayılarına yönelik bilgilerine ulaşıldı. $\mathrm{Bu}$ merkezlerin 2010 - 2020 yılları arasındaki verileri merkez, tedavi oda sayısı ve tedavi edilen hasta say1ları, oranları yıl bazlı retrospektif olarak değerlendirilmiştir. $(2,5,14,15)$

2010-2020 y1lları arasinı kapsayan toplam 10 yıllık veri Microsoft Excel, 2016 version (Microsoft Co., Menlo Park, California) yazılımı kullanılarak analiz edilmiştir.

\section{BULGULAR}

Dünyada parçacık radyoterapi sistemine sahip 2010 yılında 9 ülke varken 2020 yılında 19 ülkeye çıkmıştır. Karbon radyoterapi sistemine sahip 2010 y1lında 2 ülke varken bu rakam 2020 y1lında 5 ülkeye çıkmıştır. İnşaatı devam eden parçacık (proton, karbon) radyoterapi merkezlerinin de 2 ila 5 yıl içinde açılacağını düşünüldüğünde ilerleyen dönemde bu rakamların toplamda 25 ülkeye, karbon radyoterapi sisteminde 8 ülkeye çıkacağı görülmektedir. Planlama aşamasındaki merkezleri de değerlendirmeye aldığımızda (aktif+ inşaatı devam eden+ planlama aşamasında) toplamda 29 ülkeye, karbon radyoterapi sisteminin de 9 ülkeye çıkacağı görülmektedir. Ülke sayılarındaki yıl bazlı değişiklik tablo.1 de verilmiştir. ABD'de aktif çalışan 34, yapım aşamasında 6 ve planlama aşamasında 6 parçacık radyoterapi merkezi ile dünyada en çok merkeze sahip ülkedir. İkinci sıradaki Japonya'nın aktif 34, yapım aşamasında 6 ve planlama aşamasında 6 parçacık radyoterapi merkezi vardır. Üçüncü sırada Almayanın 8 aktif parçacık radyoterapi merkezi vardır. Ülkelerin aktif, yapım aşaması ve planlama aşamasındaki merkezleri tablo2 'te gösterilmiştir. Resim 1'de aktif merkezler harita üzerinde gösterilmiştir (25).

Tedavi merkez sayıları yönünden baktığımızda 2010 yılında toplamda 31 merkez olup bunun; 26 tanesi proton, 3 tanesi karbon ve 2 tanesi proton+ karbon tedavisi merkezi iken 2020 y1lında bu rakamlar toplamda 96 merkeze çıkmış olup bunun da 83 tanesi proton, 7 tanesi karbon ve 6 tanesi proton+ karbon tedavi merkezidir. İnşaatı devam eden merkezlerin de açılması ile bu rakamlar 2 ila 5 y1l içinde toplamda 133 merkeze çıkacak olup bunun; 115 tanesi proton, 11 tanesi karbon ve 7 tanesi proton+ karbon tedavi merkezi olacaktır. Planlama aşamasındaki merkezleri de dikkate aldığımızda (aktif + inşaatı devam eden + planlama aşamasında) toplamda 161 merkeze çıkacak olup bunun; 140 tanesi proton, 12 tanesi karbon ve 9 tanesi proton + karbon tedavi merkezidir. Aşağıda aktif, yapımı devam eden ve planlama aşamasında olan tedavi merkezlerin yillara göre ve genel durumu tablo 1, 3 ve grafik 1'de gösterilmiştir.

Parçacık (proton, karbon) radyoterapisi ile tedavi olan hasta sayıları 2010 yılında 76.266 iken 2018 yilinda bu rakam 221.528'lere ulaşmıştır. Karbon ile tedavi olan hasta sayıs 2010 y1lında 5.582 iken 2018 yılında 27.905 'lere ulaşmıştır. Yıllara göre tedavi edilen hastaların ayrıntılı dağılımları tablo 4, grafik 2ve 3 'te gösterilmiştir. Tedavi odası başı y1llık tedavi edilen yeni hasta sayılar1 protonda 86-197 yeni hasta/yıl aralığında olup karbon tedavisinde 28-211 yeni hasta/yıl aralığındadır. (Tablo 5)

\begin{tabular}{|c|c|c|c|c|c|c|c|c|c|c|c|c|}
\hline Merkez & Türü & 2010 & 2011 & 2012 & 2013 & 2014 & 2015 & 2016 & 2017 & 2018 & 2019 & 2020 \\
\hline \multirow{4}{*}{$\begin{array}{l}\text { Çalışan } \\
\text { Merkez } \\
\text { Sayıları }\end{array}$} & Proton & 26 & 29 & 30 & 35 & 40 & 46 & 56 & 60 & 69 & 77 & 83 \\
\hline & Karbon & 3 & 3 & 3 & 4 & 5 & 4 & 5 & 5 & 5 & 7 & 7 \\
\hline & Proton + Karbon & 2 & 3 & 3 & 3 & 3 & 4 & 5 & 6 & 6 & 6 & 6 \\
\hline & Toplam & 31 & 35 & 36 & 42 & 48 & 54 & 66 & 71 & 80 & 90 & 96 \\
\hline \multicolumn{2}{|c|}{ Ülke Sayı1sı } & 13 & 13 & 15 & 16 & 15 & 15 & 16 & 17 & 18 & 19 & 19 \\
\hline
\end{tabular}




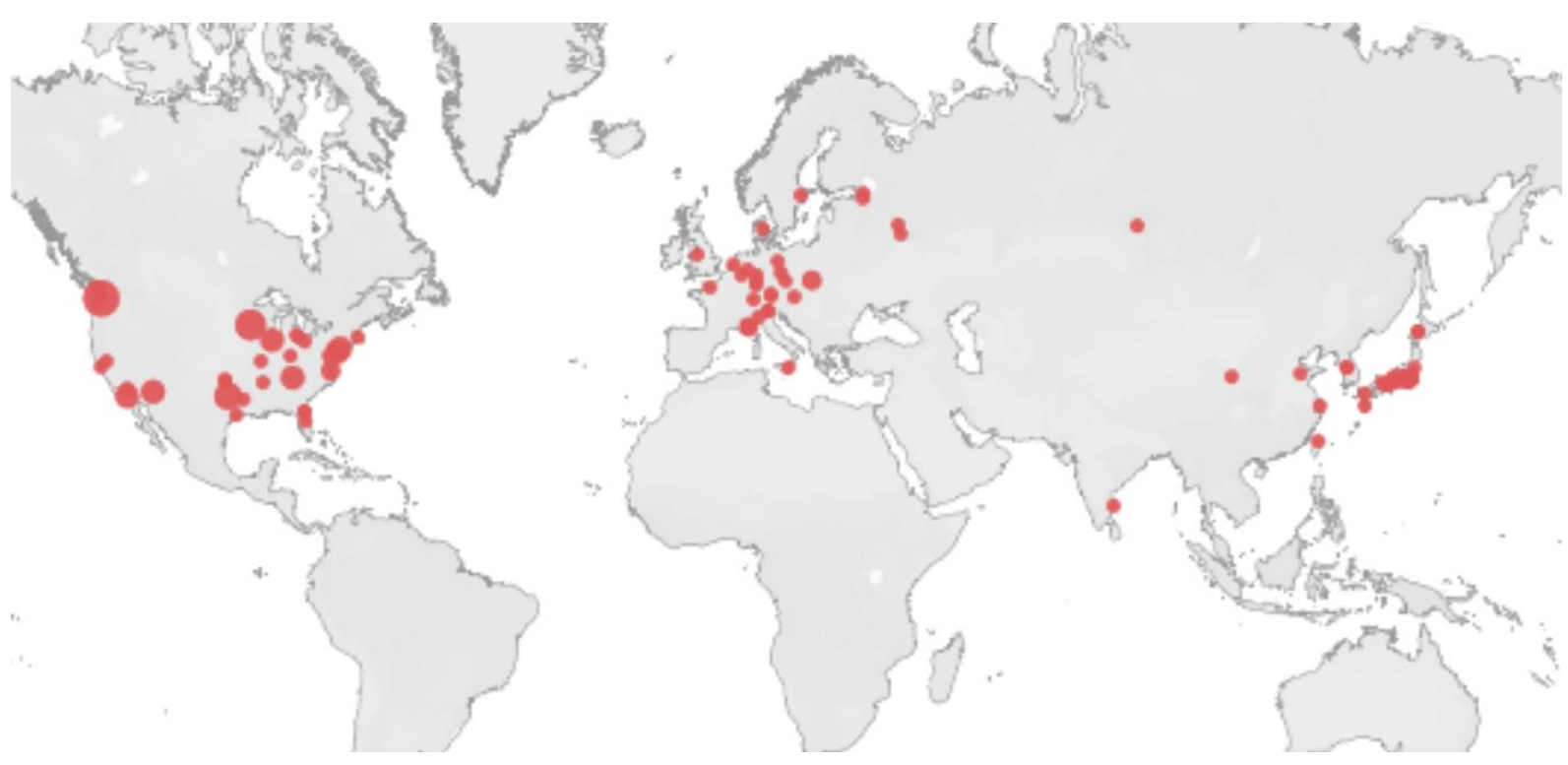

Resim 1. Dünyada Aktif Parçacık Radyoterapi Merkezleri

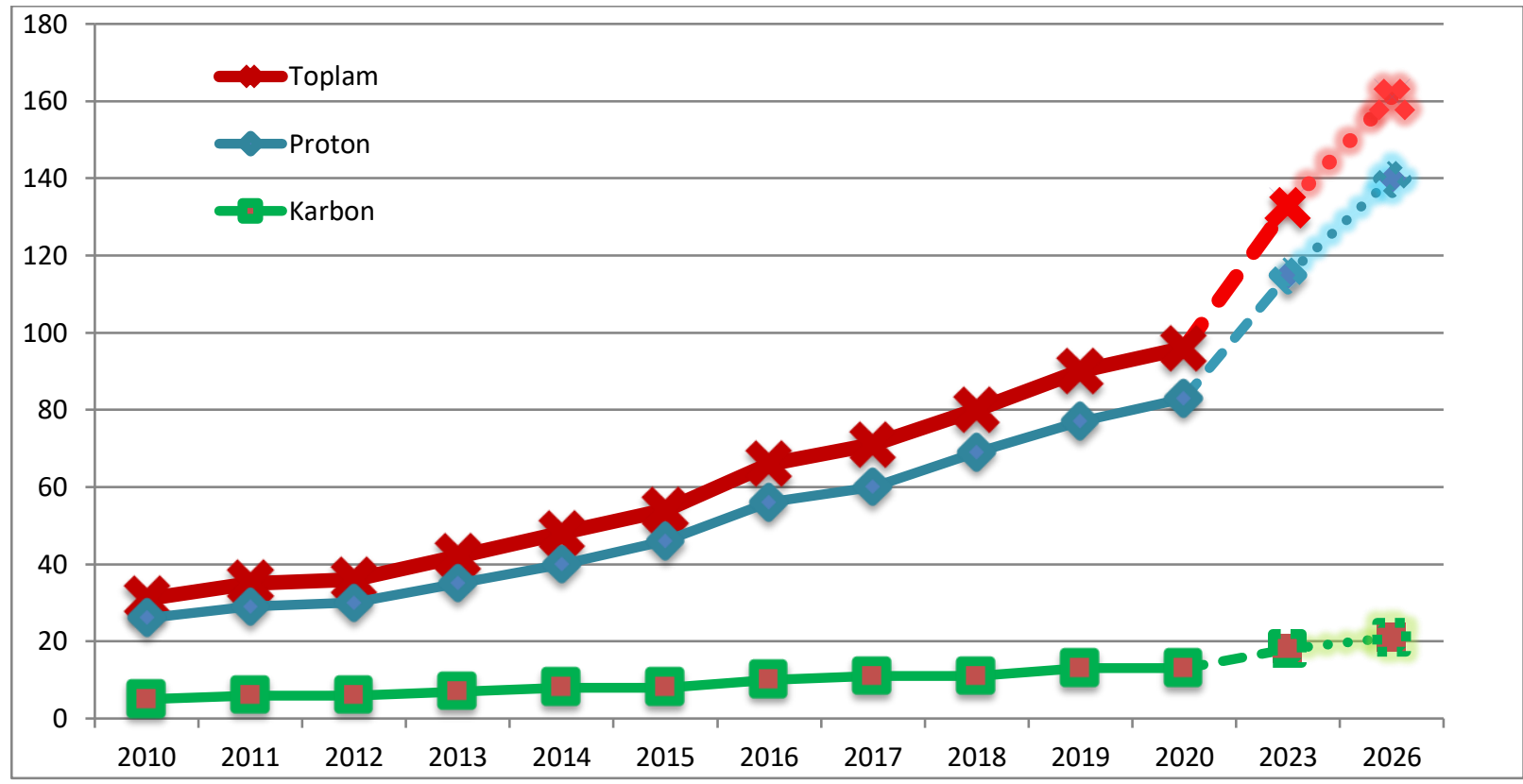

Grafik 1 Parçacık Radyoterapi Merkezlerinin Yıl Bazlı Dağılımı 


\begin{tabular}{|c|c|c|c|}
\hline & Aktif & $\begin{array}{l}\text { Yapımı devam } \\
\text { ediyor }\end{array}$ & $\begin{array}{c}\text { Planlama } \\
\text { aşamasında }\end{array}$ \\
\hline $\mathrm{ABD}$ & 34 & 6 & 6 \\
\hline Japonya & 22 & 4 & \\
\hline Almanya & 8 & & \\
\hline Rusya & 5 & 1 & 1 \\
\hline İngiltere & 4 & 2 & \\
\hline Çin & 3 & 8 & 8 \\
\hline Fransa & 3 & 1 & \\
\hline İtalya & 3 & & 2 \\
\hline Hollanda & 3 & & \\
\hline Güney Kore & 2 & 1 & 1 \\
\hline Avusturya & 1 & & \\
\hline Çek Cumhuriyeti & 1 & & \\
\hline Danimarka & 1 & & \\
\hline Hindistan & 1 & 2 & 1 \\
\hline Polonya & 1 & & \\
\hline İspanya & 1 & 1 & \\
\hline İsveç & 1 & & \\
\hline İsviçre & 1 & & 2 \\
\hline Tayvan & 1 & & 1 \\
\hline Tayland & & 4 & \\
\hline Singapur & & 2 & 1 \\
\hline Suudi Arabistan & & 1 & \\
\hline Arjantin & & 1 & \\
\hline Belçika & & 1 & 1 \\
\hline Abu Dabi Emirliği & & 1 & \\
\hline Slovak Cumhuriyeti & & 1 & \\
\hline Norveç & & & 2 \\
\hline Avustralya & & & 1 \\
\hline Misir & & & 1 \\
\hline
\end{tabular}

\begin{tabular}{|c|c|c|c|c|}
\hline Türü & Aktif Merkezler & $\begin{array}{c}\text { Yapım Assamasındaki } \\
\text { Merkezler }\end{array}$ & $\begin{array}{l}\text { Yapımı Planlanan } \\
\text { Merkezler }\end{array}$ & Toplam \\
\hline Proton & 83 & 32 & 25 & 140 \\
\hline Karbon & 7 & 4 & 1 & 12 \\
\hline Proton + Karbon & 6 & 1 & 2 & 9 \\
\hline Toplam & 96 & 37 & 28 & 161 \\
\hline
\end{tabular}


Tablo 4. Parçacık (proton, karbon) radyoterapisi ile tedavi olan hasta sayıları

\begin{tabular}{|l|l|l|l|l|}
\hline Yıl & Karbon & Proton & Diğer & Toplam \\
\hline 2010 & 5582 & 67097 & 3587 & 76266 \\
\hline 2011 & 7101 & 73804 & 3587 & 84492 \\
\hline 2012 & 9283 & 83667 & 3587 & 96537 \\
\hline 2013 & 10753 & 93452 & 3587 & 107792 \\
\hline 2014 & 13119 & 105743 & 3587 & 122449 \\
\hline 2015 & 19376 & 131240 & 3587 & 154203 \\
\hline 2016 & 21580 & 149345 & 3587 & 174512 \\
\hline 2017 & 25702 & 170556 & 3587 & 199845 \\
\hline 2018 & 27905 & 190036 & 3587 & 221528 \\
\hline
\end{tabular}

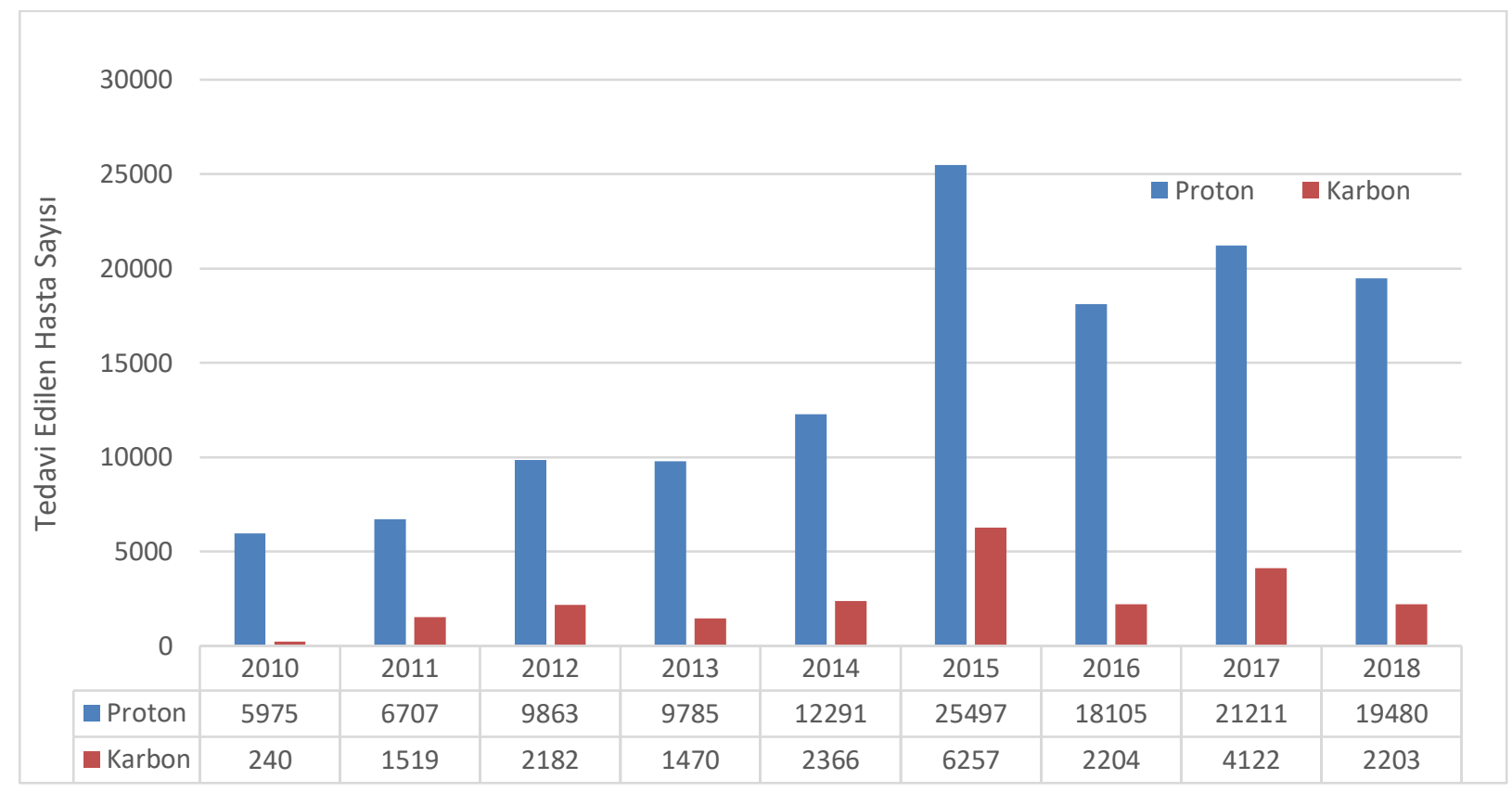

Grafik 2 Parçacık Radyoterapisi ile Tedavi Edilen Hastaların Yıllara Göre Dağılımı 


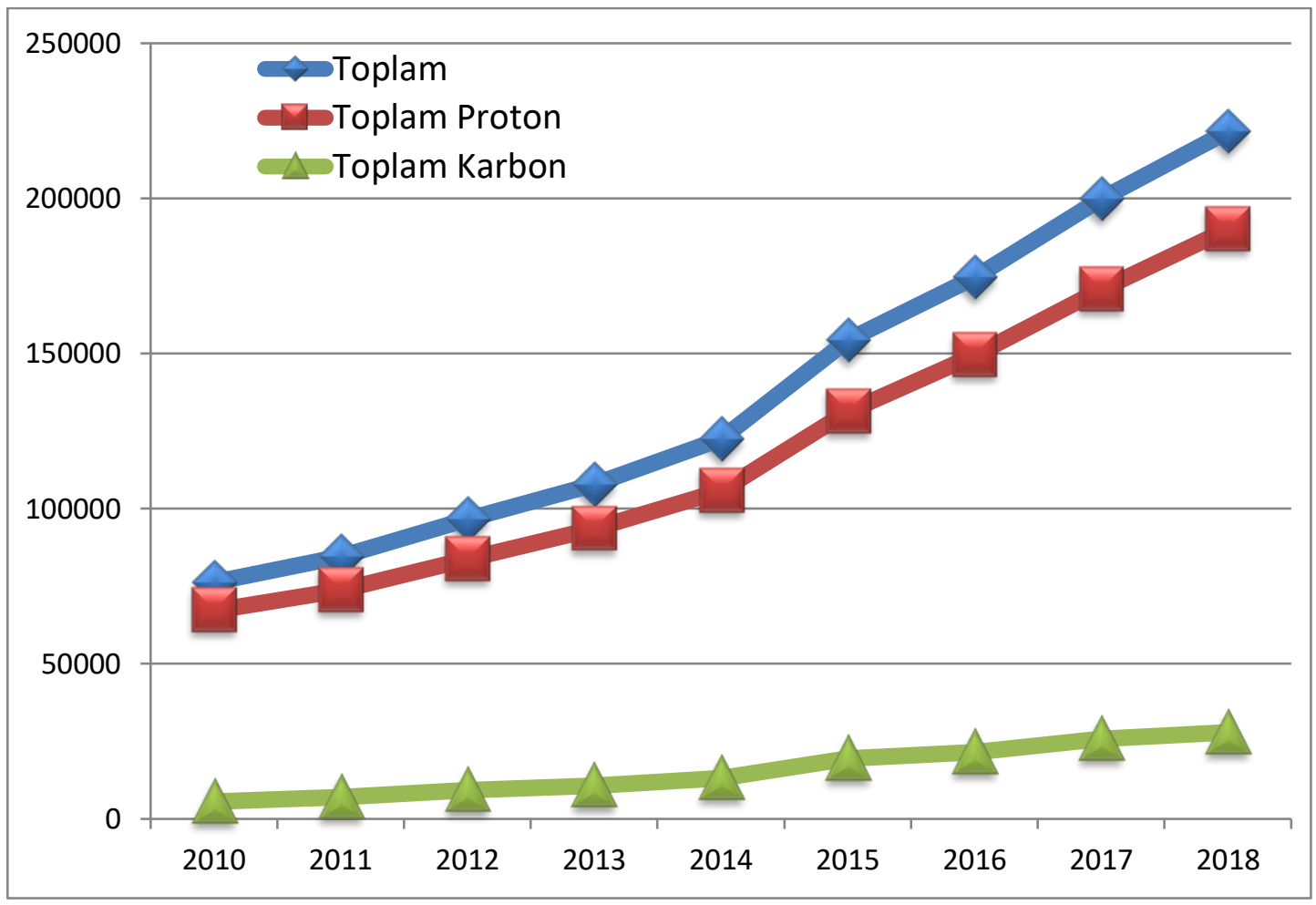

Grafik 3 Parçacık Radyoterapisi Uygulanan Hastaların Yıl Bazlı Dağılımı

\begin{tabular}{|c|c|c|c|c|}
\hline & $\begin{array}{l}\text { Proton. oda } \\
\text { sayısı }\end{array}$ & $\begin{array}{c}\text { Ortalama } \\
\text { hasta sayısı }\end{array}$ & $\begin{array}{l}\text { Karbon oda } \\
\text { Sayısı }\end{array}$ & $\begin{array}{c}\text { Ortalama } \\
\text { hasta sayısı }\end{array}$ \\
\hline 2010 & 69 & 86 & 6 & 28 \\
\hline 2011 & 76 & 88 & 6 & 133 \\
\hline 2012 & 80 & 122 & 6 & 177 \\
\hline 2013 & 93 & 104 & 14 & 72 \\
\hline 2014 & 109 & 112 & 14 & 103 \\
\hline 2015 & 128 & 197 & 18 & 211 \\
\hline 2016 & 147 & 122 & 19 & 72 \\
\hline 2017 & 153 & 137 & 20 & 123 \\
\hline 2018 & 175 & 110 & 20 & 61 \\
\hline Ortalama & & 135 & & 122 \\
\hline
\end{tabular}

\section{TARTISSMA}

1930'li yıllardan bu yana bilinmesine karşın günlük kullanıma girmesindeki gecikme, teknolojilerin pahalı ve bakım masraflarının yüksek olması gibi nedenlerden dolayı gecikmiştir. Parçacık tedavisi bilinen fotonla tedaviye göre çok farklıdır ve üstünlükleri vardır. Proton tedavisi nispeten daha kolay olmasına karşın karbon tedavisi oldukça zordur. Dünyada sadece 13 merkezde karbon tedavisi yapılmasi tedavi edilen hasta sayılarının protona göre daha az olması bunun bir göstergesidir.

Parçacık radyoterapisinin sorunu basit, yeni bir teknoloji olmamasıdır. Devasa bir teknolojidir, kompleks merkezlerin 200 milyon dolara mal olması, sadece hastaları tedavi etmekle kalmayıp, sağlık piyasalarını deforme Adress for correspondence: T.C.Sağlık Bakanlığıdr. Abdurrahman Yurtaslanankara Onkoloji Eğitim Ve Araştırma Hastanesi, Radyasyon Onkolojisi, Mehmet Akif Ersoy Mah. Vatan Cad. No: 91 Yenimahalle /Ankara Posta Kodu: 06200 
etme ve fonları diğer ihtiyaç alanlarından uzaklaştırma gücüne sahiptir. Parçacık tedavisinin kanser tedavisinde evrensel kullanımının bir engeli de, hızlandirıc1 teknolojisinin siklotron veya sinklotron ekipmanının aşırı büyüklüğü ve maliyetidir. Hızlandırıcıların boyutlarının düşmesi maliyetlerin düşmesine olumlu katk1 sağlayacaktır.

Pediatrik hastalar için, radyasyona bağlı sekellerin azaltılması bilişsel ve endokrin fonksiyonlar üzerindeki olumsuz etkileri en aza indirir ve ikincil malignite de dahil olmak üzere uzun süreli toksisite riski azaltır. Ek olarak, ekonomik analizler proton tedavisini takiben benzer foton tedavilerine kiyasla uzun süreli sağlık harcamalarında anlamlı düşüşler gösterilmiştir $(22,23)$.

Seçilen sisteme göre parçacık tedavi sistemlerinin kurulum süreleri değişmektedir. Kompakt proton sistemini kurmak firmadan firmaya göre değişmesine karşın 18-24 ay içinde kurulmaktadır. Klasik sistem dediğimiz tek hızlandırıcı ve çoklu oda sisteminin ise 36 aya yaklaşan kurulum süresi vardır. Karbon ve proton tedavi merkezi birlikte kurulmasi durumunda proton ile tedaviye başlama süresi için 36 ay karbonla tedaviye başlanması içinde ilave en az 12 ay daha gerekmektedir. Karbon henüz açık ve büyük hılandırıcılarda hızlandırılabilmektedir. Ancak küçük kapalı tip hizlandirıcilarda karbonu hizlandırma çalışmaları yapılmakta ve devam etmektedir. Bunun gerçekleşmesi ve uygulanabilir olması durumunda hem cihaz hem de inşaat maliyetleri düşecektir. Aynı zamanda daha ağır iyonların (Oksijen vb) hızlandırılmasına olanak sağlayarak bu tür iyonların tedavi yetenekleri keşfedilebilecektir. $\mathrm{Bu}$ yönde araştırmalar büyük merkezlerde devam etmekte ve planlanmaktadır. $\mathrm{Bu}$ gelişmelerde ilerleyen süreçte parçacık radyoterapisine ulaşılabilirliğini arttıracağından merkez sayısı artacaktır. $(2,15,16,17,20,21)$

Çalışmamızda da görüldüğü üzere 20102020 yıları arasında cihaz sayılarında hızlı bir artış görülmektedir. Yapım ve planlama aşamasındaki merkezleri de dikkate aldığımızda önümüzdeki 3-6 yılda cihaz sayılarının iki katına çıkacağı görülmektedir. Parçacık radyoterapisine sahip ülke sayısının 2010'da 9'a, 2020'de 19'a çıkmasıyla birlikte yapım ve planlama aşamasındaki merkezlerle birlikte parçacık radyoterapisi ile ilgilenen ülke sayısının 25'e çıkması bu hızlı artışı desteklemektedir.

Proton ve karbonun üretilmesi, kontrolü ve yönlendirilmesi yüksek maliyetlidir, 24-36 ay1 bulan uzun bir kurulum süresi vardır, teknolojik gelişmesi halen devam etmektedir. $\mathrm{Bu}$ dez avantajlarına rağmen fotondaki teknolojik gelişimi yakaladığı taktirde parçacık (proton ve karbon) tedavisi geleceğin radyoterapi modalitesi olarak görünmektedir.

Görüldügü üzere parçacık tedavi sistemlerinde dünyada hızlı bir trend yaşanmaktadır. Bunun en önemli sebepleri maliyetlerin düşmesi ve teknolojide istenilen seviyelere yaklaşılmasıdır. Bugün parçacık tedavisine bakarsak, bir sonraki adımın karbon ve diğer iyonların geniş kullanımı olacağını görürüz.

Ülkemizin bulunduğu konum itibariyle gelişmekte olan sağlı turizmde düşünüldüğünde parçacık tedavi merkezlerinin efektif kullanılacağ 1 ortadadır. 3 yıl süren kurulum süresinde sistem güncellemeleri çok rahatlıkla yapılabilir. Karar verme süreci oldukça önemlidir. Bugün karar verilmesiyle beraber ihale, inşaat, üretim, kurulum ve çalıştırma aşamaları için yaklaşık 3 yıl gibi bir süre geçtiği düşünüldüğünde karar verme aşamasında gecikilmemesi gerekmektedir. Burada önemli olan planlanan sistemin güncellenebilir özellikte olması ve hasta alım aşamasında ve daha sonrasinda en güncel özelliklerin kullanılabilmesinin sağlanmasıdır. $(2,16,17)$

2010 y1linda 76.266 hasta tedavi edilmiş. 2020 yılında rakam 221.528'e yükselmiştir. $\mathrm{Bu}$, öncelikle artan talebi karşılayabilmek için açılan merkezlerin daha fazla kullanılabilirliğinden kaynaklanmaktadır ve büyük olasılıkla gelecekte merkez başına hasta veriminde de bir artışla daha büyük bir büyüme oranına sahip olacaktır.

Bizim çalışmamızda tedavi odası başına proton için ortalama 135 (86-197) karbon için ortalama 122 (28-211) gibi çok düşük oranda yıllık yeni hasta tedavi edildiği görülmüştür. $\mathrm{Bu}$ verim düşüklüğünü sebeplerinin üretici firma, teknolojik, lojistik, operasyonel, yönetimsel, bakım onarım, eğitim, hasta potansiyeli v.b gibi nedenlerin olup olmadığ konusunda daha detaylı araştırmalara ihtiyaç 
vardır. Verimlilik arttıkça maliyetler daha da düşecektir.

Parçacık radyoterapisi için hasta kapasitesi her yıl ışınlanan tüm hastaların \% 14-15'ini olarak öngörülmüştür. Avrupa'da yapılan bu yöndeki çalışmalarda da benzer oranlara ulaşılmıştır. Çok farklı tasarlanmış bu dört araştırma aynı genel sonuçlara (\% 13-16) ulaşsa da hangi hasta alt gruplarının en fazla fayda sağlayacağı konusunda büyük farklılıklar vardır $(24,26)$. Yeni merkez planlamasinda merkezin hasta kapasitesi, hasta potansiyelleri ve uygun endikasyonların dikkate alınması atıl kapasite oluşturulmaması açısından önemlidir.

Yaşlanan bir nüfus ve artan kanser yükü ile birlikte hastalara daha iyi sonuçlar sunmaya devam ederken, artan sağlik maliyetleri ileri teknolojik cihazların temininde zorluklar neden olabilecektir ve daha maliyetli parçacık tedavi sistemlerini daha çok etkileyecektir. Hastanelerde parçacık radyoterapisi kurmanın aşırı yüksek maliyeti olmasaydı lokalize tümörü olan çoğu hasta için en çok tercih edilen tedavi modalitesi olurdu. Parçacık radyoterapisinin teknolojisi bugün bir zamanlar olduğundan çok daha kompakttır ancak IGRT özellikleri ve diğer gerekli ekipmanlarla birleştirildiğinde, piyasadaki en kompakt sistemler bile birkaç yüz metrekarelik bir alanı kaplar. Çoğu hastane, proton terapisi için özel bir bina inşa etmek için finansal kaynaklara ve alana sahip değildir. Bu nedenle fotonun en son teknolojik sistemine benzer şekilde, tek bir oda için yaklaşık 5-10 milyon \$ maliyetlerde olması gelişmesinde büyük bir ivme kazandıracaktır.

$\begin{array}{lll} & \text { Her ne kadar pediatrik ve kafatası } & \text { parçacık }\end{array}$ radyoterapisi endikasyonları konusunda fikir birliği olsa da, çoğu yetişkin hasta için ve randomize klinik çalışmalar da dahil olmak üzere yüksek kaliteli klinik kanıtların eksikliği devam etmektedir. Bununla birlikte, harici eksternal foton-tabanlı stereotaktik ablatif radyoterapi ve yoğunluk ayarlı radyoterapinin (IMRT) ilk kullanımı ve yaygınlaştırılması süreçleri randomize klinik araştırmalar olmadan gerçekleşmiştir (18). Bununla birlikte ASTRO 2014 yayınlanmış verilere dayanarak, oküler melanomlar dahil göz tümörleri, kafa tabanı kordomalar1 ve kondrosarkomlar; geleneksel radyoterapi ile medulla sipinalisin toleransının aşılabildiği omurga tümörleri ve hipofraksiyonasyon ile tedavi edilen HCC tümörlerinde öncelikle parçacık tedavisini önermektedir. Ayrıca baş ve boyun tümörleri, torasik tümörler, abdominal ve bazı pelvik tümörler gibi bir dizi başka bölge için parçacık radyoterapisinin kullanımını önermektedir (19). Karbon tedavilerinde hipofraksiyon ve hiperfraksiyon uygulamaları yapılabildiğinden hasta başı maliyetleri düşürecek daha fazla hastanın tedavi olmasına olanak sağlayacaktır.

2010'l1 y1llarda proton ve karbon tedavi sistemlerinin istenilen teknolojik gelişmeleri sağlayamaması, maliyetlerin yüksek olması ve büyük inşaat alanlarına ihtiyaç duyulması gibi sebeplerden dolayı merkez sayıs1 ile tedavi edilen hasta sayıs1 uzun süre sınırlı kalmıştır. Sağlık Bakanlığı'nın 2010 yılında hazırladığı "Türkiye'de Özellikli Planlama Gerektiren Sağlık Hizmetleri” raporunda proton tedavisinde teknolojik gelişmenin tam olarak sağlanmadığ 1 için erken olduğu ve 2012 yılında tekrar değerlendirmeye alınması gerektiği ifade edilmiştir. 2012 yılında yapılan yeni incelemeler ile teknoloji gelişmelerin istenilen seviyelere yaklaştığ 2015 y1lı ve sonrası için yeterli düzeye ulaşacağı öngörüsü ile birkaç kapsamlı onkoloji merkezine (onkoloji alanında deneyimi ve alt yapısı olan merkezler) yönelik planlama önerisinde bulunulmuştur (16,17). Zamanla parçacık tedavi teknolojilerde dönüm notalarından biri olan ve parçacık tedavi endikasyonlarının sayısını arttıran ışın vermedeki gelişmiş teknoloji "pencil beam" özelliğinin kullanılmaya başlanması, fotonla çalışan radyoterapi cihazlarının IGRT (Image Guided Radyotherapy) özelliklerinin parçacık tedavi sistemlerine uyarlanmaya başlamasıyla talep artmaya başladı. İlerleyen y1llarda talebin artmasına bağlı olarak maliyetlerin bir nebze azalması ve teknolojideki gelişmelerin parçacık tedavi sistemlerine (süperiletken teknolojisine sahip daha küçük hızlandırıcı ve daha küçük gantry sistemleri) uygulamaya girmesi sayesinde bu sistemlere olan talepler daha fazla artmaya başlamıştır. Yine benzer sebeplerden dolayı hızlandırıcı maliyetlerinin düşmesi nedeniyle tek hızlandırıcı çoklu oda olarak kullanılan klasik sistemler yerine çok daha az maliyetli ve ulaşılabilirliği çok daha kolay olan tek hizlandirıc ve tek odalı kompakt sistemler üretilmeye başlandi. Hem

Adress for correspondence: T.C.Sağlık Bakanlığıdr. Abdurrahman Yurtaslanankara Onkoloji Eğitim Ve Araştırma Hastanesi, Radyasyon Onkolojisi, Mehmet Akif Ersoy Mah. Vatan Cad. No: 91 Yenimahalle /Ankara Posta Kodu: 06200

e-mail: fatihgoksel@gmail.com

Available at www.actaoncologicaturcica.com

Copyright $\subset$ Ankara Onkoloji Hastanesi 
maliyet hem de yer darlığına kolay çözüm getiren kompakt sistemler parçacık tedavi sistemlerinin dünya üzerindeki yayılımına büyük ivme kazandırmıştır. Grafik 1 de parçacık tedavi merkezlerinin artışında 2015 y1lından sonra sıçrama olduğu görülmektedir. Ulusal planlama öngörüsünde olduğu gibi (16, 17) çalışmamızda da merkez sayılarında son bir iki y1lda taleplerde iki kattan fazla artış olduğu görülmekte, bu hızlı artış yukarıdaki gelişmelerle uyumludur.

Gelecekte parçacık tedavisindeki ağır iyonların kullanımı, arc terapi, flash terapi, MR eşliğinde parçacık tedavisi ve siklotronda ağır parçacıkların hızlandırılması gibi teknolojilerin uygulanabilir hale gelmesiyle parçacık tedavisi radyoterapinin en önemli tedavi modalitesi haline geleceği öngörülebilir.

Parçacik radyoterapisi merkezleri yüksek düzeyde eğitimli personele ihtiyaç duyduğundan, bu kadar hızlı bir gelişim için anahtar unsur eğitimdir ve dikkate alınması önemlidir.

\section{SONUÇ}

Son y1llarda ülkemiz özellikle sağlık sektöründeki gelişmeler sayesinde ve üst düzey bilgi ve deneyime sahip olmas1 nedeniyle bölgemizin referans merkezi konumuna gelmiştir. Ülkemiz bulunduğu coğrafyadan dolayı hasta turizmine uygun bir ülkedir. 2020 yılı itibariyle, ülkemize kazandırılması planlanan parçacık tedavi merkezleri ile ilgili gelişme kaydedilememiştir. Çalışmamızdan anlaşıldığı üzere parçacık radyoterapisine sahip ülke sayısı 2010 yılında 9 iken önümüzdeki birkaç yıl içinde açılması planlanan merkezlerle birlikte bu say1 katlanarak 29 ülkeye çıkacağ 1 öngörülmektedir. Yine merkez sayıs1 yönünden incelediğimizde 2010 yılında 31 merkez olmasına karşın yakın gelecekte bu sayının 161'lere kadar çıkacağ verilerinden öngörülmektedir. $\mathrm{Bu}$ artışın son birkaç y1l içinde belirgin bir şekilde katlanarak arttı̆̆1 göz önünde bulundurulduğunda ülkemizin bu teknolojiye sahip olmasının elzem olduğu görülmektedir. Ülkemizin mevcut üst düzey konumunu devam ettirebilmesi sayılı ülkede bulunan parçacık tedavisine sahip olması gereklidir.

Ülkemizin sağlık alanındaki üst düzey konumunun devam ettirilmesi amaciyla parçacık tedavisi ülkemize bir an önce kazandırılmalıdır. Proton tedavisi yanı sira daha üstün özelliklere sahip (Radyobiyolojik etkileri ve tedavi yanitları) karbon tedavisine de geçmesi gerekliği görülmektedir. Çünkü karbon iyon teknolojisi diğer ağır iyon parçacık terapilerine açık olduğundan dolayı karbon tedavi sisteminin ülkemizde olması önerilir. Karbon terapinin yapım aşamasının protona göre 2 kat daha uzun süre aldığ 1 için proton ve karbon tedavi merkezinin yapımına eş zamanlı başlanılmalıdır. Yakın zamanda proton tedavisi ile parçacık tedavisine başlanmış olunup ileriki zamanlarda karbon ve diğer ağır iyon tedavilerine geçiş yapılabilir.

$\mathrm{Bu}$ sistemlerin dünya genelinde çoğunlukla kanser alanında bilgi birikimi ve tecrübesi en üst düzey merkezlere kurulması eğilimindedir. Hasta potansiyeli, uygun endikasyon, ulaşım, multidisipliner ve multimodal tedavi yaklaşımını birlikte sağlayabildiği için öncelikle kapsamlı onkoloji merkezlerine kurulması önerilir. Öncelikle ülkemizde de onkoloji nosyonuna sahip üst düzey kanser bilgi birikimi ve tecrübesi olan kapsamlı onkoloji merkezi özelliklerine sahip Ankara ve İstanbul'da birer tane olmak üzere iki merkez ile tedavilere başlanılması önerilir. Sonraki dönemde elde edilen tecrübe, teknolojideki gelişmeler, hasta sayısı ve endikasyonlar değerlendirilerek bu merkezlerin arttırılması değerlendirilmelidir.

\section{Çıkar Çatışması: Yok}

\section{REFERANSLAR}

1. World Health Organizationl. WHO report on cancer: setting priorities, investing wisely and providing care for all. 2020.

2. Göksel F. Türkiye'de Onkoloji Hizmetleri. Koç Orhan, Güler h, Eğin ME. Özellikli Sağlık Hizmetleri ve Planlama. Ankara; Akademisyen Kitapevi; 2019:85-125

3. Lawrence Jh, Tobias Ca, Born Jl, Mccombs Rk, Roberts Je, Anger Ho, et al. Pituitary irradiation with highenergy proton beams: a preliminary report. Cancer Res 1958;18(2):121-34.

4. Wilson RR. Radiological use of fast protons. Radiology 1946;47:487-91

5. History of proton therapy. Available at: https://www. mdanderson.org/patientsfamily/diagnosis-treatment/carecentersclinics/proton-therapy-center/what-is-protontherapy/ history-of-proton-therapy.html. Accessed 15 October 2017. 
6. Dosanjh, Manjit, and Jacques Bernier, eds. Advances in Particle Therapy: A Multidisciplinary Approach. 107-1013 CRC Press, 2018.

7. Levin WP, Kooy H, Loeffler JS, DeLaney TF. Proton beam therapy. Br J Cancer 2005;93(8):84954.

8. Jakel O. State of the art in hadron therapy. In: AIP Conference Proceedings, Oahu, Hawaii: 2007. (958), p. 70-7.

9. Baumann M, Krause M, Overgaard J, Debus J, Bentzen SM, Daartz J, et al. Radiation oncology in the era of precision medicine. Nat Rev Cancer 2016;16:234e249.

10. Khan FM. The physics of radiation therapy, proton beam therapy. 4th ed., Lippincott Williams and Wilkins 2010. p. 515-531.

11. Gottschalk B. Physics of proton interactions in matter. In: Paganetti $\mathrm{H}$, editor. Proton therapy physics. USA: Taylor \& Francis Inc.; Chapther 2, 2012. p. 20-57.

12. Weber DC, Trofimov AV, Delaney TF, Bortfeld T. A treatment planning comparison of intensity modulated photon and proton therapy for paraspinal sarcomas. Int $\mathrm{J}$ Radiat Oncol Biol Phys 2004;58(5):1596-606

13. Firat, Selim, and Sachin Jogal. "Proton Therapy in the Management of Pediatric Malignant Tumors." International Journal of Hematology and Oncology 28.4 (2009): 053-057

14. https://www.heidelberg-universityhospital.com/diseases-treatments/cancer-andtumor-diseases/proton-therapy-and-carbon-iontherapy/ 2020

15. https://www.ptcog.ch/index.php/ 2020

16. T.C. Sağlık Bakanlığı 03.01.2011 tarih ve 231 sayll "Türkiye Onkoloji Hizmetleri Yeniden Yapilanma Programı 2010-2023"

17. Sağlık Bakanlığı “Türkiye'de Özellikli Planlama Gerektiren Sağlı Hizmetleri 2011-2023,
ONKOLOJİ HİZMETLERİ” , Sağlı Bakanlığı Tedavi Hizmetleri Genel Müdürlüğü, Sağllk Bakanlığı Yayın No: 836, Ankara 2011

18. Amos, R., et al. "Proton beam therapy-the challenges of delivering high-quality evidence of clinical benefit." Clinical Oncology 30.5 (2018): 280-284

19. Mohan, Radhe, and David Grosshans. "Proton therapy - Present and future." Advanced drug delivery reviews vol. 109 (2017): 26-44. doi:10.1016/j.addr.2016.11.006

20. https://ibaworldwide.com/sites/protontherapy/files/media_doc ument/iba_pt_brochure_ proteusplus_business_model_en.pdf 2020

21. https://www.mevion.com/your-proton-therapycenter/building-proton-therapy-center 2020

22. R. Mailhot Vega, "Cost effectiveness of proton versus photon radiation therapy with respect to the risk of growth hormone deficiency in children," Cancer, vol. 121, no. 10, pp. 1694-1702, 15 May 2015.

23. R. Mailhot Vega, "Cost-Effectiveness of Proton Therapy Compared to Photon Therapy in the Management of Pediatric Medulloblastoma" Int J Radiat Oncol Biol Phys., vol. 87, no. 2, p. S5, 1 October 2015

24. Bengt Glimelius, Anders Ask, Göran Bjelkengren, Thomas Björk-Eriksson, Erik Blomquist, Bengt Johansson, Mikael Karlsson \& Björn Zackrisson (2005) Number of patients potentially eligible for proton therapy, Acta Oncologica, 44:8, 836-849, DOI: $10.1080 / 02841860500361049$

25. https://dirac.iaea.org/Query/Map2?mapId=2, 2020 Schlocker, Albert J. "Considerations And Recommendations For A Centralized National Proton Therapy Institute For Israel" 2015 